\title{
Downhill varices resulting from giant intrathoracic goiter
}

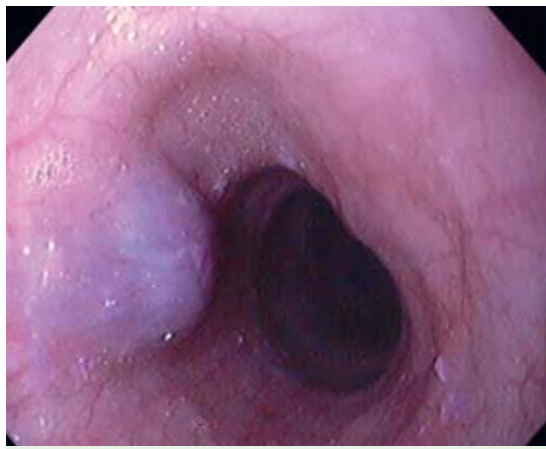

Fig. 1 Multiple submucosal veins in the upper esophagus, consistent with downhill varices.

An 82-year-old man was admitted to the hospital because of substernal chest pain, dyspnea, and occasional dysphagia to solids. His past medical history was remarkable for diabetes mellitus type II, hyperlipidemia, and Parkinson's disease. On physical examination he appeared frail but with no apparent distress. Examination of the neck showed no masses, stridor or jugular venous distension. Heart examination disclosed a regular rate and rhythm; however a 2/6 systolic ejection murmur was apparent. The lung and abdominal examinations were unremarkable, and laboratory data were within reference ranges. Myocardial ischemia was ruled out. Because of the intermittent dysphagia an esophagogastroduodenoscopy (EGD) was performed, which revealed multiple submucosal veins in the upper esophagus, consistent with downhill varices ( Fig. 1). Computed tomography (CT) of the chest found a large retrosternal goiter extending into the mediastinum ( Fig. 2). This was not treated as there was no evidence of bleeding or bleeding stigmata. The patient was offered surgical resection of the large goiter. However, due to his advanced age he preferred to be treated conservatively.

The most commonly encountered varices of the esophagus are those secondary to portal hypertension, which are found in the distal esophagus or fundus of the stomach. Portal hypertension can lead to ectopic varices, which can be found anywhere in the gastrointestinal tract, including the small bowel and colorectum [1]. However, ectopic varices related to portal hypertension are almost never found in the proximal esophagus. Proximal esopha-

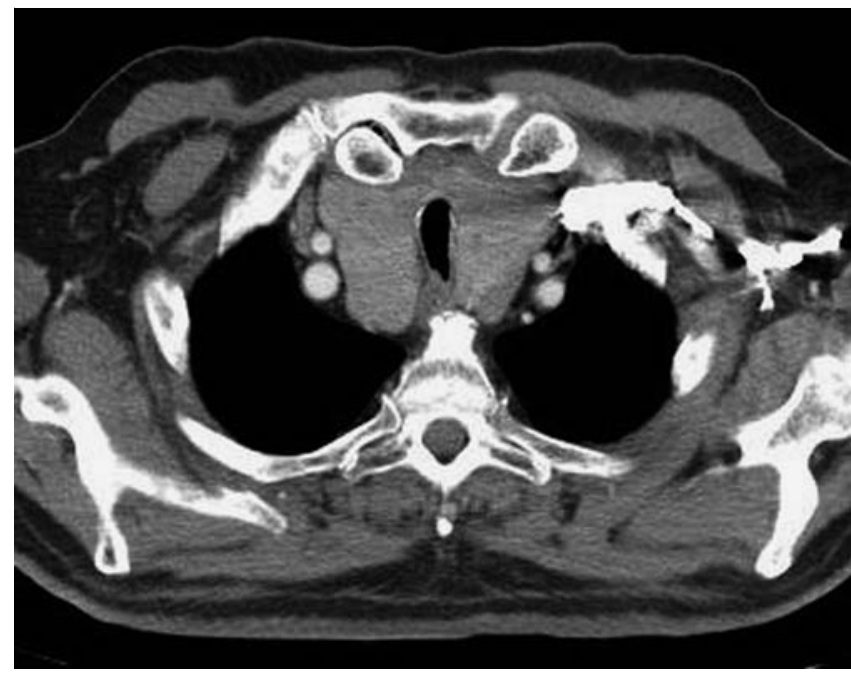

Fig. 2 Sagittal computed tomography of the chest. The goiter was immense, reaching the aortic arch, surrounding the trachea and partially compressing the upper esophagus. The esophagus was additionally compressed by anterior spinal spondylophytes.

geal varices are called "downhill varices", as they are located in the upper esophagus and project downwards. Downhill varices occur as a result of shunting in cases of upper systemic venous obstruction from space-occupying lesions in the mediastinum $[2,3]$. Downhill varices as a result of mediastinal processes are reported to occur in up to $50 \%$ of patients $[3,4]$. In our patient, the presence of downhill varices led to the discovery of a giant intrathoracic goiter. Blood from the thyroid plexus flows through the inferior thyroid veins into the brachiocephalic vein [4]. In cases of obstruction of the thyroid veins, blood flows via the deep esophageal veins, resulting in proximal varices. Although these varices usually do not bleed, occasionally they can result in catastrophic hemorrhage. In cases of bleeding, endoscopic band ligation or angiographic therapy is recommended as injection of sclerosants can result in systemic embolization through the brachiocephalic vein [5].

\section{Endoscopy_UCTN_Code_CCL_1AB_2AC_3AG}

\section{K. Mönkemüller ${ }^{1}$, D. Poppen ${ }^{1}$, K. Feld-} mann $^{2}$, L. J. Ulbricht ${ }^{3,4}$

1 Department of Internal Medicine and Gastroenterology, Marienhospital Bottrop, Bottrop, Germany

2 Department of Radiology, Marienhospital Bottrop, Bottrop, Germany

3 Department of Cardiology, Marienhospital Bottrop, Bottrop, Germany

${ }^{4}$ University of Witten/Herdecke, Witten, Germany

\section{References}

1 Kotfila R, Trudeau W. Extraesophageal varices. Dig Dis 1998; 16: 232 - 241

2 Basaranoglu M, Ozdemir S, Celik AF et al. A case of fibrosing mediastinitis with obstruction of superior vena cava and downhill esophageal varices: a rare cause of upper gastrointestinal hemorrhage. J Clin Gastroenterol 1999; 28: $268-270$

3 Calderwood AH, Mishkin DS. Downhill esophageal varices caused by catheter-related thrombosis. Clin Gastroenterol Hepatol 2008; 6: e1

4 van der Veldt AA, Hadithi M, Paul MA et al. An unusual cause of hematemesis: Goiter. World J Gastroenterol 2006; 12: 5412-5415

5 Tsokos M, Bartel A, Schoel R et al. Fatal pulmonary embolism after endoscopic embolization of downhill esophageal varix. Dtsch Med Wochenschr 1998; 123: 691 - 695

Bibliography

DOI $10.1055 / \mathrm{s}-0029-1215290$

Endoscopy 2010; 42: E40

(c) Georg Thieme Verlag KG Stuttgart · New York ISSN 0013-726X

\section{Corresponding author}

\section{J. Ulbricht, MD, PhD}

University of Witten-Herdecke

Departments of Internal Medicine and Cardiology Marienhospital Bottrop

Josef-Albers-Str. 70

46236 Bottrop

Germany

Fax: +49-20-411061009

ludger.ulbricht@mhb-bottrop.de 